\title{
An Investigation into the Participation of Hearing Impairment Learners in Physical Education and Sports in Lusaka and Central Provinces of Zambia
}

\author{
Nephat Kasebusha ${ }^{1 *}$, Martin Banda, $\mathbf{P h D}^{2}$ \\ ${ }^{I}$ Kapiri Girls National Technical Secondary School Kapiri Mposhi \\ ${ }^{2}$ University of Edenberg Kitwe
}

\author{
*Corresponding Author: Nephat Kasebusha, Kapiri Girls National Technical Secondary School Kapiri \\ Mposhi, Zambia
}

\begin{abstract}
The purpose of the study was to find out the participation of hearing impairment learners in physical education and sports. The study was conducted in Lusaka district of Lusaka province and Kabwe district of Central province of Zambia. The study conceptualized the participation of the HI learners in PES. The study employed both the qualitative and quantitative research methods to collect, integrate and analyze data. The study utilized descriptive research design. The target population of the study were all HI teachers and HI learners. The sample size for the study was 62 respondents. The purposive sampling was used to select the HODs and the secondary schools were the study was conducted while the simple random sampling was used to select the HI learners and HI teachers. The research instruments used in the study were questionnaires and interview guide. Data was collected through the administration of questionnaire and interview methods. Excel software version 2013 to generate descriptive statistics in the form of frequency tables, bar graph and pie charts in order to give clear explanations, presentation and interpretation of quantitative data. Qualitative data was analyzed by using thematic method in order to generate themes. The study shows that there was a low participation of HI learners in PES. The sports facilities were of poor standard. The study found that there were challenges which hinder the participation of HI learners in PES.
\end{abstract}

Keywords: Impairment, Physical Education Hearing Impairment, learners, teachers, participation, sports, Lusaka, Central, province, Zambia.

\section{INTRODUCTION}

\subsection{Background}

According to the World Health Organization (WHO), hearing loss is the fourth highest cause of disability globally and in Zambia (World Health Organization, 2012, Zambia Disability Survey, 2015). Over $5 \%$ of the world's population or 466 million people has disabling hearing loss (432 million adults and 34 million children) (Schmucker, Kapp, Motschall, 2019; WHO, 2020). It estimated that by 2050 over 900 million people or one in every ten people will have disabling hearing loss. In Zambia, hearing impairment is the fourth most common occurring impairment after physical, visual and cognitive limitations.

Disabling hearing loss refers to hearing loss greater than 40 decibels in the better hearing ear in adults and a hearing loss greater than $30 \mathrm{~dB}$ in the better hearing ear in children. The majority of people with disabling hearing loss live in low- and middle-income countries such as Zambia (WHO, 2020). The prevalence in this age group is greatest in South Asia, Asia Pacific and sub-Saharan Africa. A person who is not able to hear as well as someone with normal hearing - hearing thresholds of $25 \mathrm{~dB}$ or better in both ears is said to have hearing loss. Hearing loss may be mild, moderate, severe, or profound. It can affect one ear or both ears and leads to difficulty in hearing conversational speech or loud sounds. Hard of hearing' refers to people with hearing loss ranging from mild to severe. People who are hard of hearing communicate through spoken language and can benefit from hearing aids, cochlear implants, and other assistive devices as well as captioning. People with more significant hearing losses may benefit from cochlear implants. 'Deaf' people mostly have profound hearing loss, which implies very little or no hearing. They often use sign language for communication. 
Hearing impairment (HI) among children has been dealt with in various studies based on three perspectives: severe, profound and mild hearing loss. Profound hearing loss in children is estimated to be at 1 to 6 out of every 1000 children. In most cases, these children, like any other child, need to access and take part in regular physical education and sports (PES). The main reason for participation is to enjoy the benefits associated with sport participation (WHO, 2019). Studies have shown that sports participation elevates self-esteem and minimizes the negative feelings associated with deafness (Martin \& Bat, 2003). According to Murphy (2008), sport plays a significant role in the lives and communities with special needs in a similar way it does for people without disabilities. However, marginalized groups, including the deaf, face challenges of getting involved in sport.

The benefits of engagement in PES to learners with H.I. cannot be overemphasized. Various studies over the past three decades such as Lieberman and Pecorella (2006), have revealed that participation in sports leads to enhanced functional status and life quality among people with selected disabilities. Katiwa (2008) studied the efficacy of using structured physical exercise as an intervention for managing stereotyped behaviours in autism. The study sampled 34 autistic children at the Nairobi special unit, in Nairobi Kenya. The results showed that structured physical exercise programme had a positive impact on the characteristic stereotype behaviour on autism at the Nairobi Autism Unit. The physical activity links to the improvement of human psychic, affective, social, cognitive and motor development. Many studies have shown that moderate-intensity physical activities have significant health benefits (WHO, 2019; Zeng, 2017). Physical activity reduces the risk of cardiovascular disease, diabetes, depression, obesity; while the lack of physical activity increases it (WHO, 2019, Cook, 2013). Thus these activities may bring psychological and physiological benefits (e.g. health promotion, feelings expression, the formation of critical awareness, autonomy development, and motivation for study, among others.

A number of physiological, social, psychological and mental advantages are associated with regular participation in sporting activities (Weiss, 2000). Riungu (2002) conducted a study at Kaaga School for the Deaf aimed at establishing the impacts of physical education and sports on deaf children's fitness. Riungu's research found out that participation in sports assisted deaf children to improve fitness, flexibility, strength, low body fat, social interaction, and self-concept. Murphy (2008) notes that the most frequently used indicator of emotional wellbeing is self-esteem, with sports and physical activities being essential boosters. Ilic and Nikolić (2012) point out more benefits of participating in sports such as improved humour, enhanced self-esteem, increased body appearance and energetic feelings, improved self-confidence in both mental and physical abilities and reduced stress. Ajwang' (2008) carried out a case study in Kenya to determine whether physical education was effective in improving health-related levels. After eight-week participation in physical education, results indicated that physical activity did improve health-related fitness of the pupils.

In the United States of America, learners with disabilities, especially with hearing impairment, are limited to various sporting activities (Kyle, 2009). Despite this significant milestone, persons with disabilities, including those with hearing impairments, still encounter many issues related to sports participation since disability even reduce bad attitudes in most schools. In Pakistan, Muhammad (2011) found that several methodologies in sports activities were utilized by regular schools to engage learners with hearing impairment in sports. These include; provision of adequate play materials and equipment to learners and employment of games coaches with sign language capability to correspond with learners during practice.

Several reasons have been given for the motives of participation in sports among students in various schools in South Africa. According to Salman (2012), engagement in inter-school competitions among the students with hearing impairment varies according to such factors as desire to learn more skills, a way of relieving boredom, and opportunities for competition, a sense of belongingness, gaining celebrity status, financial benefit and improvement of health. This is a clear indication that sports participation satisfies both physical and psychological needs. Choosing a sport that will always remain interesting is very important among students with hearing impairment. The best sport for students with hearing impairment is one that the student finds fun and exciting to participate in (Hill and Hannon, 2008). To encourage a healthy and active lifestyle, it is necessary to expose students to a variety of sports and let their desires and abilities act as a guide to further commitment (Hill and Hannon, 2008). Students with hearing impairment are likely to enjoy the sport more if allowed to learn in a relaxed atmosphere while having fun and receiving support and encouragement from adults. 
Gender has been noted to be a significant variable to participation in sports among students with hearing impairment in most secondary schools (UNESCO, 2017). According to Larkin (2007), it is common in all countries that girls and women have less probability of participating in sport than males. It is a fallacy to anticipate that girls and women do not wish to engage in games. Factors such as lack of accessibility, safety, poverty, burden of domestic chores, inadequate sport and recreation facilities deter female students from participation in sports

The policy emphasizes the provision of quality PES for all pupils, including those with disabilities such as hearing impairment. However Pupils and parents interviewed in Southern, Lusaka and Northwestern provinces complained of negative attitudes that include rejection, overprotection and a general lack of conducive PES environment for pupils with disabilities (MoGE and UNESCO, 2017). The infrastructure in schools is not user friendly to pupils with disabilities, and there is no proper equipment for disabled persons. While teachers might know about adapted PES, the numbers of pupils in classes are too big. In some schools, one class has over 80 pupils, which is impossible for one PES teacher to handle. There is minimal and inept research being done on PES in general in Zambia and specifically on the participation of H.I. learners in Zambia. The current study seeks to establish the variables which influence participation in sports among students with hearing impairment in secondary schools in Zambia.

\subsection{Statement of the Problem}

Participation in sport and PE in particular by learners with hearing impairment is anchored globally in the United Nations Convention on Rights of Persons with Disability (2006) Article 30.5 and domesticated locally in the Zambia Persons with Disability Act of 2012. The goal is to enhance participation in sports among persons with disabilities, including students. Participation in physical education improves health-related fitness of children with disability. Despite the existence of great emphasis on sports and health, there is a concern that learners with disabilities do not frequently participate in sports. Low competency in of sign language and inadequate physical education equipment and materials are some of the problems that limited teachers from executing instructional skills and strategies to learners with HI The assumptions that people with hearing impairment do not have a visible disability, and therefore should similarly participate in sports to their hearing counterpart's forms the basis for the current study. Thus, this study aims at evaluating the determinants of PES participation among learners with hearing impairment when at school. It further seeks to determine the kinds of PES activities that learners with HI participate in, their motivation to participate in such sports activities and available sports facilities as enablers for participation in PES among students with hearing impairment.

\section{CONCEPTUAL FRAMEWORK}

Reiche and Ramey (2011) define a conceptual framework as a set of broad ideas and principles taken from relevant fields of enquiry and used to structure a subsequent presentation. Therefore, the study was conceptualized.

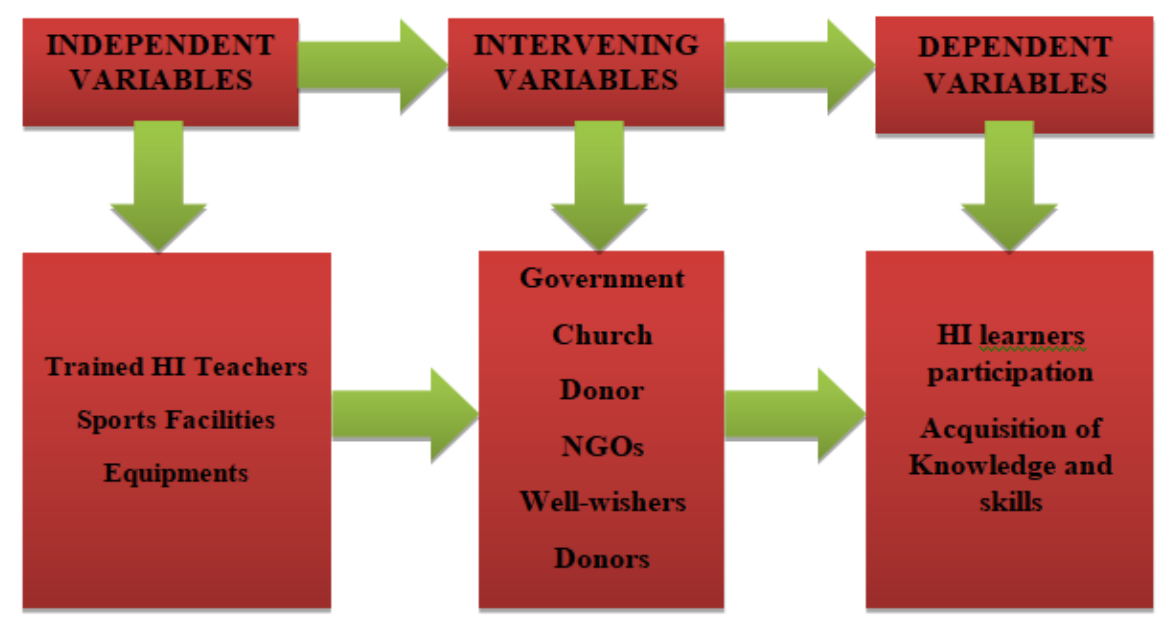

Figure1. Conceptual Framework

Source: Field Model, 2012 
The availability of sporting activities and preference of games play a crucial role in learners' participation in sports. In this case, learners would prefer to participate in sports whose facilities are available and functional. Preference for sports among learners may improve the intensity and frequency of participation in PES. In a school with the availability of sports facilities, equipments and well trained HI teachers, learners tend to participate, acquire knowledge and develop practical sports skills. Intervening variables such as type, degree and time of onset of the hearing loss, internal motives (intrinsic factors) and external motives (extrinsic factors) complement the independent variables with respect to participation in sports by students. The interplay between intervening factors determines participation in sports by students with a hearing impairment which is the study's dependent variable. In the absence of the trained HI teachers, physical facilities and equipments, the government, church, NGOs, well-wishers and donors intervene by providing the needed requirements for HI learners to fully participate in sports activities.

\section{LITERATURE REVIEW}

\subsection{World View}

According to Musengi and Chireshe (2012), hearing loss affects between $4 \%$ and $5 \%$ of the world population. Sherrill (2004) describe the hearing loss as hard of hearing or deaf concerning the extent of the damage. Types of hearing loss were examined based on three perspectives: sensor neural, mixed hearing loss and conductive (Sherrill, 2004). Children with hearing loss are likely to have a higher risk of deficits in balance compared with children who are typically developing. The effect is more pronounced in those who have sensor neural hearing loss since the inner ear is affected by this type of hearing loss.

In a study by Riungu (2002), sports and physical education did improve strength, flexibility, and cardio-respiratory endurance of the students with hearing impairment who participated. Hearing loss can also be classified depending on the time of onset. The categories include the prelingual and postlingual Deaf. Chimedza and Petersen (2003) note that the earlier the hearing loss manifests itself in a child, the harder he or is likely to develop the spoken language. The delay in a language is associated with Deaf and adversely impact negatively on the child's social development. One adverse effect of language delay is low self-concept. Deaf children find it difficult, during play, to understand the game rules and make themselves understood by peers. They often feel confused, unworthy, frustrated, and may opt to withdraw from participating in sports activities. Missing childhood play is missing an opportunity to develop social skills. The child disenfranchised from establishing and maintaining peer relationship through playing.

Ramos (2008) argues that children are oriented to play games related to their gender roles. Traditionally, boys are encouraged and expected to play complex games which involve strategy and strength. They are also taught how to work towards specific goals and promote negotiations to settle disputes encountered during play. Girls, on the other hand, are discouraged from competitive activities. They engage in waiting for turns to perform simple repetitive activities such as jumping ropes or playing hopscotch. Male students show the tendency for team sports and generally competing, while female students prefer aerobic and dance. In order to make physical education more exciting and successful, opinions and attitudes of students are more than appreciated, and it is they who can influence the introduction of all sorts of new programs such as aerobics, yoga, dances, badminton, rowing and so on. A variety of sports and recreational activities makes it possible for everyone to find adequate physical activity given their anthropological characteristics, motor skills and motivation for participating. The current study has looked at gender, sport type, availability of sports facilities, motivation, and participation frequency as a factor which can influence participation.

Studies have shown reasons for sports participation among students with a hearing impairment which include enjoyment or having fun, spending time with friends, improving fitness, developing competence and gaining new opportunities (Andreff, 2001). Participation in Sports leads to improved health-related fitness levels. According to Riungu (2002), issues related to physical health are at the apex as obesity rates are becoming high globally, a condition affecting people regardless of age. It was reported in 2008 that over 40 million children of below five years and 1.4 billion adults were obese (WHO, 2013). The report recommended that young people should engage in sports to minimize their chances of becoming over-weight. Additionally, adults can enhance their health and substantially 
prevent the occurrence of chronic diseases such as diabetes, high blood pressure, osteoporosis, cancer and cardiovascular diseases through regular exercise (Riungu, 2002; Stewart and Ellis, 2013). Keeping physical fitness was considered by the current study as one of the motivating factors for participation in sports.

\subsection{Regional View}

The importance of sport participation cannot be overemphasized among the Deaf; hence the sports facilities are fundamental and must be provided in every learning institution for the Deaf. The outcomes of a study done by Quick, Simon and Thornton (2010) revealed that schools in England provided resources required for 46 unique games to both young ladies and young men with a mean of 25.6 games in regular secondary schools and 17.6 in special schools. A study in Egypt which sampled 48 football players from a registered sports club established as scale through which motivation to exercise football game among the Deaf was measured, and motivation factors were scored (Demir, 2003). The study found that motivation was controlled by rewards, fame, societal relations, physical fitness and health challenges. This study highlights several factors that determine children's participation in sports depending on the environment of the learning institution and facilities provided. Similarly, the current study sought to find out motivational factors to sport participation in the selected secondary schools of the Deaf in Kenya, which have a different environment with regard to the provision of sports facilities.

In Kenya, the Ministry of Education (2009) created an SNE arrangement that highlights the significance of comprehensive instruction of learners with exceptional needs. The Government's initiative was to give and finance discussions to learners with different needs to take an interest in cocurricular exercises to upgrade social incorporation. The assets were to be utilized to adjust the materials and hardware for co-curricular activities. The current study takes into consideration the relationship between the availability of sports facilities and other variables like participation and preference.

Mwangi (2012) conducted a study based on the use of selected instructional methods in physical education and its impacts on sports participation among children with hearing impairment in special units in public primary schools in Nairobi County, Kenya. The study revealed that the use of appropriate instructional strategies and facilities improved children's participation in sports. The study concluded that as far as physical education is concerned, individual safety guideline for the exercise of students is the most significant to be established during practice.

Andreff (2001) investigated the database of the International Committee of Sports for the Deaf for data on Deaflympics participants. The study reported comparatively low participation and a gradual increase in participation in Deaflympics by the developing countries. The low participation is mostly attributed to a relatively small size of the governing body (some with only two full-time staff at the national office) and over-reliance on volunteers to run Deaflympics affairs in these countries. It was found that $23 \%$ of the developing countries have never taken part in the sports with Africa taking the largest share of 13 out of 35 non-participating countries.

An important consideration is the inclusivity of PES in Zambian schools for those with disabilities and across gender. While the Government has made great efforts to enhance the girl-child's participation in the education system, girls especially those with disabilities continue to face challenges in PES as a result of traditional cultural norms that regard PES as a male endeavour. The policy emphasizes the provision of quality PES for all pupils, including those with disabilities such as hearing impairment. However Pupils and parents interviewed in Southern, Lusaka and North-western provinces complained of negative attitudes that include rejection, overprotection and a general lack of conducive PES environment for pupils with disabilities (MoGE, MYSCD and UNESCO, 2017). The infrastructure in schools is not user friendly to pupils with disabilities, and there is no proper equipment for disabled persons. While teachers might know about adapted PES, the numbers of pupils in classes are too big. In some schools, one type has over 80 pupils, which is impossible for one PES teacher to handle.

The 2017 situational analysis of physical education and sport (PES) in Zambia indicates that Physical Education is described under the umbrella term of Physical Education and Sport or PES (MoGE and UNESCO, 2017). The Ministry of General Education (MoGE) is the custodian of PES in Zambia in 
An Investigation into the Participation of Hearing Impairment Learners in Physical Education and Sports in Lusaka and Central Provinces of Zambia

line with the Education Act of 2011. The National Policy on Education elucidated in the Zambia Education Curriculum Framework of 2013 provides a clear and detailed national strategy of PES at all levels: Early Childhood Education, Primary Education, Secondary Education and Teacher Education.

\section{Methodology}

The mixed research paradigm (qualitative and quantitative research methods) was used to collect, integrate and analyze data. These methods helped to maximize the strength and minimized the limitations or weaknesses of each other. Therefore complemented each other during the study, hence data collected was reliable. The descriptive research design was used to integrate various components of the study in a coherent and logical manner in order to effectively address the research problem. The descriptive research design was used to collect the experiences, feelings, views, opinions and thoughts of the respondents on the participation of the hearing impairment (HI) learners in Physical Education (PE) and Sports.

The sample population were all heads of department, teachers and hearing impaired learners of the selected schools of Lusaka and Kabwe districts. The sample size was 62 respondents. The questionnaire was used as both an instrument and method of collecting quantitative data. They helped to collect data from the vast areas, uphold respondents' confidentiality and enabled respondents express their views freely. The interview guide was used as an instrument to collect qualitative data while the interview was used as a method. The interview method enabled the researchers to test information from respondents by cross examination, hence detailed and reliable data was obtained.

\section{RESEARCH FINDINGS AND DISCUSSION}

\subsection{Benefits for HI learners' participation in PES activities}

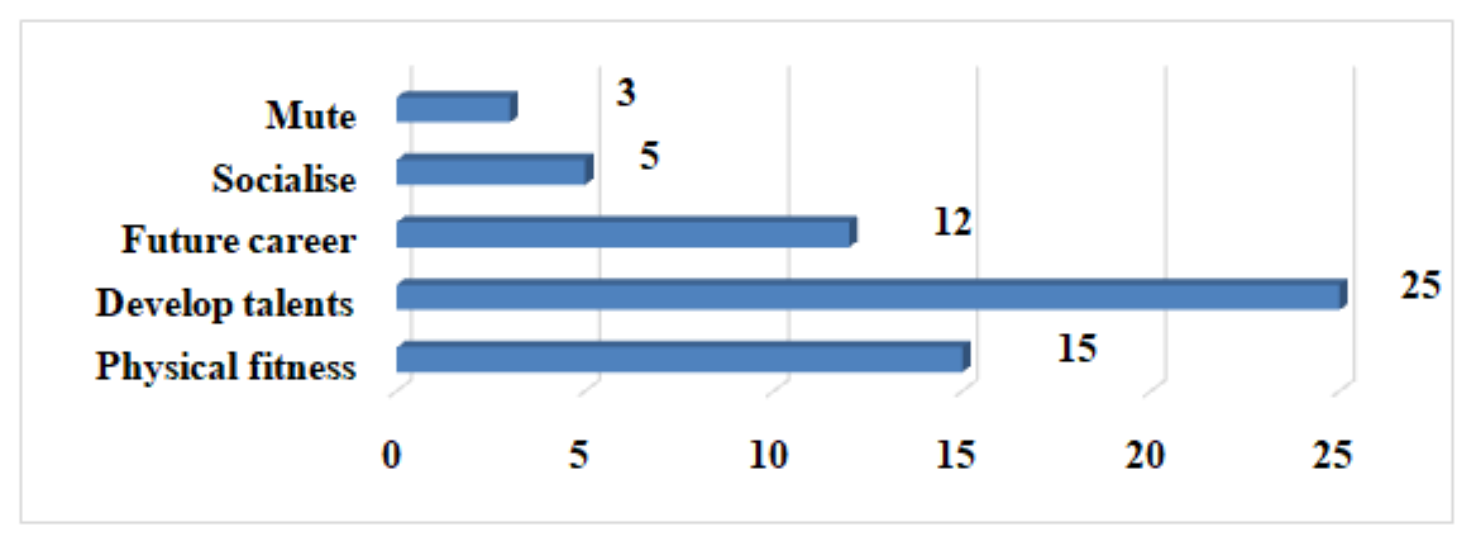

Figure1. Benefits for HI learners' participation in PES $\quad N=60$

\section{Source: Field Work, 2020}

This study showed that $41.7 \%$ of the respondents reported that there are benefits for the HI participation in PES activities. The HI learners participate in PES for their body physical fitness the participation in PES activities would help them develop their talents, develop their future career and the learners would help them to socialize with others. The participation of HI learners in PES would enable them to develop their talents and skills so that in future they become self-reliant. It can also be a source of income for them when they fully develop their sports skills. The study support Riungu (2002) whose study revealed that sports and physical education did improve strength, flexibility and cardio respiratory endurance of the disabled children.

The aim of the introduction of PES in schools for all learners regardless of the status and ability one has was to make them acquire and develop a skill or talent so that they become relevance or useful in society in future before and after the completion of their education. Therefore, the HI learners are highly encouraged to participate in the sports activities in order for them to prepare for their future practical career and this can only be achieved when a learner start to practice it when still young. It is therefore important to indicate that through sports participation, it helps develop and enhance their sports talents and keeps them busy and away from the streets. The learners with HI are encouraged to participate in sports activities for socialization purpose as well. Through participating in sports, the HI learners are able to make new friends and be accommodated, for example when they play with the 
An Investigation into the Participation of Hearing Impairment Learners in Physical Education and Sports in Lusaka and Central Provinces of Zambia

regular learners they get to socialize and feel a sense of belonging. The interaction of HI learners with learners who are not HI helps to break the barrier between the normal and the HI children in schools. It is for this reason that inclusiveness and integration of all learners in schools regardless of the ability and disability that one has should be highly encouraged.

The other respondent from the interview also reported that: "the participation of HI learners in PES would enable them to develop their talents and skills so that in future they become self-reliance. It can also be a source of income for them when they fully develop their sports skills." (Head of Department: Expressive Arts)

\subsection{Extent to which the HI learners participate in PES activities}

Table1

\begin{tabular}{|c|c|c|}
\hline Response & Frequency & Percentage \% \\
\hline School inter house competition & 45 & 75 \\
Inter school competition & 6 & 10 \\
Inter zone competition & 0 & 0 \\
Inter district competition & 0 & 0 \\
Inter province competition & 0 & 0 \\
Mute & 9 & $\mathbf{1 0 0}$ \\
\hline Total & $\mathbf{6 0}$ & $\mathbf{1 0 0}$ \\
\hline
\end{tabular}

Source: Field Work, 2020

$\mathrm{N}=60$

About $75 \%$ of the respondents reported that the HI learners end up at the school inter house sports competition while $10 \%$ of the respondents indicated that they go upto the inter school level competition. The HI learners they even perform better than the able bodied or the normal learners in sporting activities. However, they cannot fully participate in sports competition as no HI learners. The findings of this study were contrary to the findings of Mwangi (2009) that there was a low disability participation in sports competition as compared to the able bodied learners. This study argued that schools put in place deliberate school policy in order to motivate and support learners with $\mathrm{HI}$ to participate in sports activities. The school allow the HI learners to participate in the school sports competition up to the national level. These school deliberate policies help to engage the learners into sports affairs. The schools highly encourages the learners to fully participate in PES as it is also part of the career pathway for learners. This helps the learners to take part by including them in school teams in all disciplines of sport. The HI learners seem to perform well in this type of sport unlike the academic pathways. The all-inclusiveness policy makes it possible for them to take part. The learners seem to do better than the regular learners in sport and enjoy the outdoor activities. It is with this view that they should be encouraged to participate more in sports.

According to Wood (2010), the learners with HI are sidelined to fully participate in the Physical Education and sports competition. This has been attributed by the nature of their being. The majority of the respondents indicated that they only end up with the inter school houses competition. This implies that the learners with HI are not selected by schools for them to participate in inter school sports competition at various levels due to their impairment. The HI learners may have sports skill and talent to compete with the regular learners but they are not recognized by school that they have the ability and potential to perform just like any other learner. The study shows that there is a low HI learners' participation in sports competition. It is also important to argue that the inadequate or unavailability of sports facilities demotivate $\mathrm{HI}$ learners from participating in sports activities.

The two respondents interviewed reported that, "the HI learners they even perform better than the able bodied or the normal learners in sporting activities. They participate in school inter houses, inter school competition, inter district, inter provincial and national sports competition. The school put in place a deliberate school policy in order to motivate and support learners with HI to participate in sports activities. The school allow the HI learners to participate in the school sports competition up to the national level." (Heads of Departments: Expressive Arts)) 
An Investigation into the Participation of Hearing Impairment Learners in Physical Education and Sports in Lusaka and Central Provinces of Zambia

\subsection{Challenges faced by Hearing Impaired (HI)learners in participating in Physical Education and Sports}

Table2. Challenges faced by HI learners in participating in PES

\begin{tabular}{|c|c|c|}
\hline Response & Frequency & Percentage \% \\
\hline Discrimination & 13 & 21.7 \\
Self Stigmatization & 11 & 18.3 \\
Lack of consideration & 4 & 6.7 \\
Lack of school and family support & 7 & 11.7 \\
Communication challenge & 15 & 25.0 \\
Lack of motivation by the school & 3 & 5.0 \\
Inadequate sports facilities & 5 & 8.3 \\
Lack of exposure & 2 & 3.3 \\
\hline Total & $\mathbf{6 0}$ & $\mathbf{1 0 0}$ \\
\hline
\end{tabular}

Source: Field Work, $2020 \quad \mathrm{~N}=60$

There are various challenges that hinder the participation of HI learners in sports activities, these ranges from discrimination, self-stigmatization, lack of consideration, lack of support school and families, communication challenge, lack of motivation by the school, inadequate sports facilities and lack of exposure. The HI learners would actively participate in the sports competition activities. However, there is a challenge of communication barrier. The HI learners cannot interact properly with the normal learners of the challenge of the sign language. Lack of trained teachers to handle learners with HI in PES. The teachers found it difficult to communicate in sign language in order to communicate to HI learners. The study confirmed the report made by Riungu (2002) that there was no improvement in balance after the subjecting the disabled learners for eight (8) weeks to sporting activities. In this case, the trained teachers for HI are not trained in PES, hence the challenges. This study argue with the findings by Mwisuka (2010) whose study noted that in disability related challenges, there seems to be a lack of consistent data because the consistent of data does not guarantee the participation of HI leaners in the sporting activities. The teachers trained in PES were not trained to handle learners with HI, it's really a great challenge to engage HI learners in the sports activities.

The learners would want to participate in PES but the environment itself was not favourable for them because it was meant for the normal or regular learners. Besides this, the disability itself hinders them because of the poor balance. The other challenges which hinders the HI learners from participating in sports activities is the discrimination by the sports administrators in schools. The HI learners are regarded that they cannot compete at the same level with the regular learners. Therefore disability discriminate themselves from participating in the sports activities. The study therefore agreed with the recommendation that was made by Mwiingu (2009) that teachers should mind that children with disabilities may not prefer to engage in physical activities due to the notion that it is hard for them to maintain with their non-disabled peers when conducting sports programmes. The HI learners are discriminated by other learners and some teachers who feel that they cannot perform as the regular learners, this contribute to low participation in the sports competition. The other challenge in the sports administration that prevents the HI learners to participate in sports is that they discriminate themselves. Donney (2003) argued that one aspect of language delay is slow self-concept. The deaf children find it difficult during play to understand the game rules and make themselves understand with their friends as a result a child develops low esteem. The self-discrimination indeed contribute to the non-participation of HI learners in sports because they feel that they cannot compete with the normal friends in sports. It is important to note that the HI learners initiate the self-stigmatization, hence reluctant to perform in the sporting activity. They fail to freely mix and interact with other normal learners. They feel unappreciated compared to normal children in the sense that their participation does not be recognized and noticed. This contribute to the discrimination of the HI learners' participation in sports. In other words the HI learners feel inferior of the normal learners, hence the non-participation in sports competition.

One of the respondents interviewed reported that, "the HI learners they even perform better than the able bodied or the normal learners in sporting activities. They participate in school inter houses, inter school competition, inter district, inter provincial and national sports competition. The school put in 
An Investigation into the Participation of Hearing Impairment Learners in Physical Education and Sports in Lusaka and Central Provinces of Zambia

place a deliberate school policy in order to motivate and support learners with HI to participate in sports activities. The school allow the HI learners to participate in the school sports competition up to the national level." (Head of Department: Expressive Arts)

The two respondents who were interviewed reported that, "the HI learners would actively participate in the sports competition activities. However, there is a challenge of communication barrier. The HI learners cannot interact properly with the normal learners of the challenge of the sign language. Lack of trained teachers to handle learners with HI in PES. The teachers found it difficult to communicate in sign language in order to communicate to HI learners. The trained teachers for HI are not trained in PES. The teachers also trained in PES were not trained to handle learners with HI, it's really a great challenge engage them in sports activities." (Heads of Department: Expressive Arts)

\subsection{Strategies to Enhance Participation of HI Learners in PES Activities}

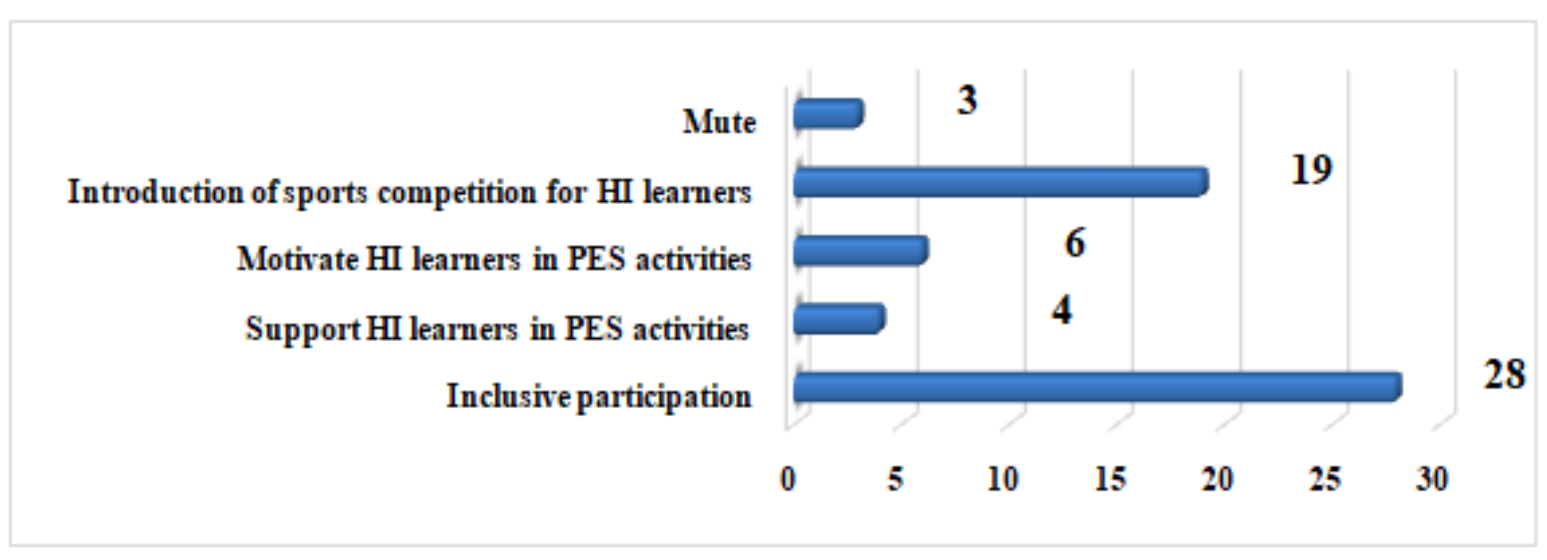

Figure2. Strategies to enhance participation of HI learners in PES

Source: Field Work, 2020

$\mathbf{N}=60$

About $28 \%$ of the respondents suggested inclusive participation of HI learners in PES activities and the training of teachers in both PES and Hearing Impairment. The inclusive participation of both the normal and HI learners in sports activities, HI learners should be supported by both the schools and families and the HI learners need to be motivated to enhance their full participation in sports. The introduction of sports competition among the HI learners in schools up to the national level. There is need for trained teachers specifically to handle the HI learners in PES. This will help them easy acquisition and development of talents and skills among learners with HI challenge. The HI players are left out because of their nature. There is need to make sports team for HI players to motivate and encourage them fully participate in sports competition. In addition, there is need to form a national team for HI players with the HI coach.

The respondents interviewed also suggested that, "there is need for trained teachers specifically to handle the HI learners in PES. This will help them easy acquisition and development of talents and skills among learners with HI challenge. The HI players are left out because of their nature. There is need to teams for HI players to motivate and encourage them to fully participate in sports competition. There is need to form a national team for HI players with the HI coach." (Head of Department: Expressive Arts)

\section{CONClusion}

The HI learners participate in Physical Education and Sports for their body physical fitness, the participation in PES activities help them develop their talents, future career and help them to socialize with others. The participation of HI learners in PES would enable them to develop their talents and skills so that in future they become self-reliant. It can also be a source of income for them when they fully develop their sports skills. The HI learners participate in the schoolinter house competition, inter school competition, inter zone competition, inter district competition and inter province competition. The HI learners faces various challenges which included discrimination, self-stigmatization, lack of consideration, lack of support school and families, communication challenge, lack of motivation by the school, inadequate sports facilities and lack of exposure. The inclusive participation of both the normal and HI learners in sports activities, HI learners should be supported by both the schools and 
families, the HI learners need to be motivated to enhance their full participation in sports the introduction of sports competition among the HI learners in schools up to the national level. There is need for trained teachers specifically to handle the HI learners in PES. This will help them easy acquisition and development of talents and skills among learners with HI challenges.

\section{REFERENCES}

[1] Ajwang, R. (2008). Effectiveness of physical education programme on health-related fitness of the physically challenged pupils. Unpublished Master's Thesis, Kenyatta University, Nairobi, Kenya.

[2] Andreff, W. (2001).The Correlation between Economic Underdevelopment and Sport, European Sport Management Quarterly.

[3] Chimedza, R. and Petersen, S. (2003). Disabilities and Special Needs Education in an African Setting. Harare: College Press.

[4] Demir, C. (2003). Impacts of Demographic Variables on the Preference of Sports Activities Carried Out by Undergraduate Students: an Implication from Egypt. Journal of Sport and Tourism, 8(4): 312.

[5] Hill, H and Hannon, J, C. (2008). An Analysis of Middle School Students Physical Education Physical Activity Preferences. Physical Educator, 65(4): 195.

[6] Ilić-Stošović, D and Nikolić, S. (2012). Motor Skill Performance of Children with Sensory Impairment: Learning Disabilities. Wichian Sittiprapa porn. In Tech International platform on sport and development (IPSD) Sport and disability.

[7] Katiwa, E. (2008). The effect of a physical exercise programme on the stereotype behaviour and response among autistic children at the Nairobi unit. Unpublished Master's Thesis, Kenyatta University, Nairobi, Kenya.

[8] Kyle, W. (2009). Inclusive Education for Hearing Impaired: Education Core Studies 100: University of Regina.

[9] Lieberman, L, J and Pecorella, M. (2006). Activity at home for children and youth who are deaf-blind. Journal of visual impairment and blindness, 97 (12): 768.

[10] Martin, D and Bat-Chava, Y. (2003). Negotiating Deaf-Hearing Friendships: Coping Strategies of Deaf Boys and Girls in Mainstream Schools. Child Care Health, 7(25): 67

[11] Muhammad, B, H and Muhammad, A.N. (2011). Assessing the Role and Importance of Co-curricular Activities in Special People (Hearing Impaired Learners) Learning at Elementary level: European Journal of Adapted Physical Activity, 2(7): 38.

[12] Musengi, M and Chireshe, R. (2012). Inclusion of Students with hearing impairment in Mainstream Rural Primary Schools in Zimbabwe: Challenges and Opportunities. Stud Tribes Tribals, 10(2): 116.

[13] Mwangi, J, W. (2009). "Special educators' use of selected instructional strategies in physical education in special units in public primary schools in Nairobi County". Unpublished Master's Thesis, Narobi: Kenyatta University.

[14] Simon, L and Thornton, K. (2010). Deaf young people and their families. Cambridge: Cambridge University Press.

[15] Ramos M.G. (2008). Wellbeing in Deaf Children: A Framework of Understanding. The British Psychological Society Educational \& Child Psychology, Vol 25 No 2

[16] Riungu, K. (2002). The effects of Physical Education and Sports program on deaf pupils' health-related fitness. Unpublished Master's Thesis, Kenyatta University, Nairobi, Kenya.

[17] Weiss, M, R. (2004). Developmental Sport and Exercise Psychology: A Lifespan Perspective. Morgantown, WV: Fitness Technology.

[18] Whyte, G.P, Harries, M and Williams, C. (2005). ABC of Sports and Exercise Medicine. Blackwell Publishing Ltd, USA.

[19] Woods, C, B and Tannehill, D. (2010). Children's Sport Participation and Physical Activity Study (CSPPA).Research Report No, 1. School of Health and Human Performance, Dublin City University and Irish Sports Council, Dublin, Ireland.

[20] WHO (2007). International Classification of Functioning, Disability and Health. Geneva: WHO.

[21] World Health Organization (2013). Obesity and Overweight (Factsheet No. 311).

[22] WHO, World Health Organization (2019). Global Strategy on Diet, Physical Activity and Health. 
An Investigation into the Participation of Hearing Impairment Learners in Physical Education and Sports in Lusaka and Central Provinces of Zambia

[23] Zeng, N and Ayyub, M. (2017). Effects of Physical Activity on Motor Skills and Cognitive Development in Early Childhood: A Systematic Review. Biomed Research International, 2017.

Citation: Nephat Kasebusha, Martin Banda, PhD. "An Investigation into the Participation of Hearing Impairment Learners in Physical Education and Sports in Lusaka and Central Provinces of Zambia" International Journal of Humanities Social Sciences and Education (IJHSSE), vol 8, no. 9, 2021, pp. 71-81. doi: https://doi.org/10.20431/2349-0381.0809007.

Copyright: () 2021 Authors. This is an open-access article distributed under the terms of the Creative Commons Attribution License, which permits unrestricted use, distribution, and reproduction in any medium, provided the original author and source are credited. 